\title{
Thalamomuscular Coherence in Essential Tremor: Hen or Egg in the Emergence of Tremor?
}

\author{
DD David J. Pedrosa, ${ }^{1}{ }^{-}$Eva-Lotte Quatuor, ${ }^{1}$ Christiane Reck, ${ }^{1}$ K. Amande M. Pauls, ${ }^{1}$ Carlo A. Huber, ${ }^{1}$ \\ Veerle Visser-Vandewalle, ${ }^{2}$ and Lars Timmermann ${ }^{1}$ \\ ${ }^{1}$ Department of Neurology and ${ }^{2}$ Department of Stereotactic and Functional Neurosurgery, University Hospital Cologne, 50924 Cologne, Germany
}

\begin{abstract}
Thalamomuscular coherence in essential tremor (ET) has consistently been detected in numerous neurophysiological studies. Thereby, spatial properties of coherence indicate a differentiated, somatotopic organization; so far, however, little attention has been paid to temporal aspects of this interdependency. Further insight into the relationship between tremor onset and the onset of coherence could pave the way to more efficient deep brain stimulation (DBS) algorithms for tremor. We studied 10 severely affected ET patients (six females, four males) during surgery for DBS-electrode implantation and simultaneously recorded local field potentials (LFPs) and surface electromyographic signals (EMGs) from the extensor and flexor muscles of the contralateral forearm during its elevation. The temporal relationship between the onset of significant wavelet cross spectrum (WCS) and tremor onset was determined. Moreover, we examined the influence of electrode location within one recording depth on this latency and the coincidence of coherence and tremor for depths with strong overall coherence ("tremor clusters") and those without. Data analysis revealed tremor onset occurring $220 \pm 460 \mathrm{~ms}$ before the start of significant LFP-EMG coherence. Furthermore, we could detect an anterolateral gradient of WCS onset within one recording depth. Finally, the coincidence of tremor and coherence was significantly higher in tremor clusters. We conclude that tremor onset precedes the beginning of coherence. Besides, within one recording depth there is a spread of the tremor signal. This reflects the importance of somatosensory feedback for ET and questions the suitability of thalamomuscular coherence as a biomarker for "closedloop" DBS systems to prevent tremor emergence.
\end{abstract}

Key words: deep brain stimulation; essential tremor; neurophysiology; thalamus; wavelet cross-spectrum

\section{Introduction}

Neural oscillations and the balance of synchronization and desynchronization play an important role in physiological pro-

Received Jan. 9, 2014; revised Sept. 11, 2014; accepted Sept. 13, 2014.

Author contributions:D.J.P., C.R., and L.T. designed research;D.J.P., E.-L.Q., C.R., K.A.M.P., and V.V.-V. performed research; D.J.P., E.-L.Q., C.R., K.A.M.P., C.A.H., and L.T. contributed unpublished reagents/analytic tools; D.J.P., E.-L.Q., C.A.H., and L.T. analyzed data; D.J.P., E.-L.Q., K.A.M.P., C.A.H., V.V.-V., and L.T. wrote the paper.

This work was supported by the Köln Fortune Program and the German Research Foundation [DFG, Klinische Forschergruppe KF0 219 (Ti 319/2-1)]. We gratefully acknowledge the help of Dr. Esther Florin for data assessment and data analysis, Dr. Mohammad Maarouf for DBS electrode placement surgery on some of the patients and for providing some of the target coordinates, and Dr. Ville Mustonen for his help with the wavelet analyses. Moreover, we gratefully acknowledge the extensive help and patience of Prof. Martin Hellmich of the Institute of Medical Statistics, Informatics and Epidemiology in Cologne for his advice with statistical questions. Finally, we thank Dr. Anna Pedrosa and Pedro Pedrosa for their valuable discussions and comments. Wavelet software was modified from the software package by C. Torrence and G. Compo, available at http://paos.colorado.edu/research/wavelets/, and from the software package by Jeremy Bigot et al., available at http://www.math.univ-toulouse.fr/ bigot/.

D.P. has occasionally received honoraria from Medtronic and Bayer Healthcare for lecturing at conferences or consulting work. C.R. works for Medtronic but declares no conflicts of interest. L.T. received payments as a consultant for Medtronic, Boston Scientific, Bayer Healthcare, UCB Schwarz Pharma, and Sapiens. L.T. has received honoraria as a speaker on symposia sponsored by TEVA Pharma, Lundbeck Pharma, Bracco, Gianni PR, Medas Pharma, UCB Schwarz Pharma, Desitin Pharma, Boehringer Ingelheim, GlaxoSmithKline, Eumecom, Orion Pharma, Medtronic, Boston Scientific, Cephalon, Abbott, and GE Medical. The institution of L.T., not L.T. personally, has received funding by the German Research Foundation, the German Ministry of Education and Research, Manfred und Ursula Müller Stiftung, Klüh Stiftung, Hoffnungsbaume, NBIA Disorders Society USA, Köln Fortune, Medtronic, UCB Schwarz Pharma, Bayer Healthcare, Zur Rose Pharma, Abbvie, Archimedes Teva, and Deutsche Parkinson Vereinigung. The authors declare no other competing financial interests.

Correspondence should be addressed to Dr. med. David J. Pedrosa, Department of Neurology, University Hospital Cologne, Joseph-Stelzmann-Str. 9, 50924 Köln, Germany. E-mail: david.pedrosa@uk-koeln.de.

DOI:10.1523/JNEUROSCI.0087-14.2014

Copyright $\odot 2014$ the authors $\quad 0270-6474 / 14 / 3314475-09 \$ 15.00 / 0$ cesses. Hence, accurate working of the motor system relies upon optimal information processing between cortical and subcortical structures and their respective connections from and to the periphery. It is therefore not surprising that distinct movement disorders, such as poverty of movement in Parkinson's disease (Brown, 2003) or essential tremor (ET; Schnitzler et al., 2009) are associated with abnormal patterns of synchronization. In ET, this synchronization is particularly striking as patients develop limb oscillations with a $4-8 \mathrm{~Hz}$ frequency during postural or intentional tasks (Deuschl et al., 1998). The mechanisms leading to increased synchronization between brain areas and muscles eventually manifesting as tremor remain, however, poorly understood.

There is a growing body of evidence for a central origin of ET. This was already hypothesized due to the lack of dependence of tremor on peripheral reflex mechanisms with inertia changes (Elble et al., 1987; Deuschl et al., 1996). Later, imaging studies corroborated the importance of the CNS in ET, indicating hyperactivation of the cerebellum or the inferior olivary nucleus (Jenkins et al., 1993; Wills et al., 1994) but also as coherence between muscles and the motor system could be proven during tremor (Schnitzler et al., 2009). While tremor research traditionally focused on the detection of single oscillators responsible for tremor emergence, recent investigations have challenged this view, proposing instead a collaboration of different areas in an oscillating "tremor network" (Raethjen and Deuschl, 2012). 
Table 1. General patient demographics, disease characteristics, and number of heights and trajectories

\begin{tabular}{|c|c|c|c|c|c|c|c|c|}
\hline Patient & Sex & $\begin{array}{l}\text { Disease } \\
\text { duration (years) }\end{array}$ & $\begin{array}{l}\text { Age } \\
\text { (years) }\end{array}$ & $\begin{array}{l}\text { Tremor } \\
\text { frequency }(\mathrm{Hz})\end{array}$ & $\begin{array}{l}\text { Testing } \\
\text { hemisphere }\end{array}$ & Trajectories & $\begin{array}{l}\text { Target coordinates } \\
\left(X^{*}, Y, Z\right)\end{array}$ & $\begin{array}{l}\text { Recording } \\
\text { heights }\end{array}$ \\
\hline 1 & $\mathrm{~m}$ & 45 & 67 & 5.1 & VLp right & $C, A, P, L$ & $11.2,-7.8,-2.4$ & 8 \\
\hline 2 & $\mathrm{f}$ & 15 & 73 & 4.8 & VLp left & $C, A, P$ & $11.3^{*},-7.1,-5.1$ & 10 \\
\hline 3 & $\mathrm{~m}$ & 31 & 61 & 4.8 & VLp right & $C, L$ & $11.7,-6.9,-0.9$ & 6 \\
\hline 4 & $\mathrm{f}$ & 20 & 69 & 5.8 & VLp right & $C, A, M, P, L$ & $10.8,-7.4,-1.6$ & 8 \\
\hline 5 & $f$ & 15 & 62 & 3.7 & VLp left & $C, A, M, P, L$ & $13.1^{*},-8.4,-3.1$ & 5 \\
\hline 6 & $\mathrm{~m}$ & 19 & 62 & 4.9 & VLp right & $C, A, M, P, L$ & $10.9,-5.9,0.1$ & 11 \\
\hline 7 & $f$ & 20 & 55 & 4.6 & VLp right & $C, M, P, L$ & $10.1,-6.0,-5.1$ & 9 \\
\hline 8 & $\mathrm{~m}$ & 14 & 72 & 3.4 & VLp right & $C, A, M, P, L$ & $12.2,-5.7,-0.4$ & 9 \\
\hline 9 & $f$ & 11 & 75 & 3.6 & VLp left & $C, P, L$ & $11.9^{*},-5.9,-0.1$ & 10 \\
\hline 10 & $\mathrm{f}$ & 18 & 60 & 4.9 & VLp left & $C, A, M$ & $10.5^{*},-7.1,-1.4$ & 10 \\
\hline Mean $\pm S D$ & & $20.8 \pm 10.1$ & $65.6 \pm 6.6$ & $4.56 \pm 0.76$ & & $3.9 \pm 1.1$ & $11.4^{*} \pm 0.88,-6.8 \pm 0.92,-2.0 \pm 1.9$ & $8.6 \pm 1.90$ \\
\hline
\end{tabular}

$\mathrm{m}$, Male; f, female; C, central; $A$, anterior; $M$, medial; $P$, posterior; L, lateral.

*Contacts located on the left hemisphere are negative per definition. For this study, all contacts were converted to positive values.

This tremor network involves cortical and subcortical brain structures and shows coherence with trembling muscles (Schnitzler et al., 2009). However, interdependencies are not necessarily permanent but, in the case of corticomuscular coherence, rather constitute a fluctuating phenomenon (Raethjen et al., 2007). At any rate, the exact pathophysiological mechanisms inside this network are not merely of scientific interest, as the identification of all components and their interactions could pave the way for more specific treatment options, such as more refined deep brain stimulation (DBS) algorithms. In this context, Cagnan et al. (2013) have recently reported that thalamic DBS is most efficient when applied according to a specific signal phase once tremor has emerged. This emphasizes the increasing focus on demanddriven DBS approaches (Rouse et al., 2011). On the other hand, it also illustrates the present lack of suitable biomarkers of imminent tremor onset for demand-driven DBS to prevent tremulous activity.

One possible candidate for such an indicator might be thalamomuscular coherence, as it has been detected consistently during tremor (Marsden et al., 2000; Schnitzler et al., 2009). As there was no coherence during rest in our previous results (Pedrosa et al., 2012), we hypothesized the onset of thalamomuscular coherence after tremor onset. We therefore analyzed ET patients undergoing thalamic DBS surgery with time-resolved spectral techniques of local field potentials (LFPs) and simultaneous electromyographic (EMG) recordings. The aim of this study was to answer the question whether onset of thalamomuscular coherence during postural tremor is "hen or egg," i.e., precedes tremor or is its consequence.

\section{Materials and Methods}

Patients. We studied 10 patients (six females and four males) suffering from medically refractory ET according to the diagnostic criteria (Deuschl et al., 1998) with a mean disease duration of $20.1 \pm 10.1$ years. All patients underwent bilateral implantation of DBS electrodes into the posterior parts of the ventrolateral thalamus (VLp) or in areas just below the thalamus. The indication for electrode implantation was based on the recommendations of the German Deep Brain Stimulation Study Group (Sixel-Döring et al., 2009). At the time of surgery, patients' mean age was $65.6 \pm 6.6$ years (for more demographic details, see Table 1 ).

The study was approved by the local ethics committee (study no. 09-051) and carried out in accordance with the Declaration of Helsinki. All patients gave their written informed consent for intraoperative recordings.

Planning and implantation. Electrodes were implanted at the Department of Stereotactic and Functional Neurosurgery in Cologne. The exact procedure during surgery has been described in prior publications ( $\mathrm{Pe}-$ drosa et al., 2012). Briefly, the VLp was targeted on the basis of Schalten-
brand-Wahren atlas coordinates (Schaltenbrand et al., 1977). Standard coordinates for targeting the lower border of the VLp were as follows: (1) $5.5 \mathrm{~mm}$ posterior to the midcommissural point in the $y$-axis, (2) at the level of the line between the anterior and the posterior commissure in the $z$-axis, and (3) $14-14.5 \mathrm{~mm}$ lateral to midline ( $x$-axis). Electrode placement was performed with a Riechert-Mundinger system (Inomed Medizintechnik) and, for five patients, the target was located on areas below the thalamus as this region has been proven to be more efficacious in tremor suppression (Blomstedt et al., 2009; Barbe et al., 2011). Target coordinates for individual electrode placement are also summarized in Table 1.

We used intraoperative microelectrode recordings to localize the optimal implantation area, eventually basing the final placement of the DBS electrode on single-cell activity as well as on the profile of tremor reduction and side effects during intraoperative test stimulation.

Intraoperative recordings. Intraoperative recordings were performed with a commercially available recording system (Inomed Micro Electrode Recording System; software: MER 2.4 beta). We used 2-5 concentrically configured micro-macroelectrodes (central, anterior, medial, posterior, and lateral) with a distance of $2 \mathrm{~mm}$ from the central electrode each. LFPs were obtained during the motor paradigm over a distance of $6-12 \mathrm{~mm}$ in steps of $1 \mathrm{~mm}$. Data were recorded from $4-8 \mathrm{~mm}$ above the target point to $1-2 \mathrm{~mm}$ beyond the planned target, i.e., in or near the posterior subthalamic area (not the subthalamic nucleus).

The intraoperative motor paradigm consisted of two conditions: (1) patients rested their arm in a comfortable position (rest condition) for $30-60 \mathrm{~s}$ and (2) patients were asked to elevate and hold their forearm contralaterally to the implantation side at an angle of $\sim 30^{\circ}$ and to spread their fingers (hold condition) for 30-60 s. Thereby, tremor emerged immediately after the elevation of the arm. Subjects performed both tasks sequentially while awake and without speaking or performing any other activities. We simultaneously recorded activity of the extensor [extensor digitorum communis (EDC)] and flexor [flexor digitorum longus (FDL)] muscles of the contralateral forearm using surface EMG electrodes. Sedation (remifentanil and/or propofol) was withdrawn $\geq 15$ min before beginning the recordings.

Both LFP and EMG signals were bandpass filtered between 0.5 and 1 $\mathrm{kHz}$ during the recording and preamplified with gains of $2000 \times$ and $200 \times$, respectively. Resolution of recordings was 12 bit and data were sampled at $2.5 \mathrm{kHz}$.

Electrode localization. Localization of active contacts used for stimulation was carried out by analyzing postoperative high-resolution computed tomography scans and/or intraoperative stereotactic skull $\mathrm{x}$ rays (anteroposterior and lateral) for every patient. Imaging was then reimported into the planning software (STP 3.0 and STVX, Stryker Leibinger) for superimposition on preoperative MRI, resulting in stereotactic coordinates.

Data analysis. LFP and EMG activities were stored offline and imported into Matlab 2012b (MathWorks). All recorded tracks were inspected visually and trials containing noise or movement artifacts were 

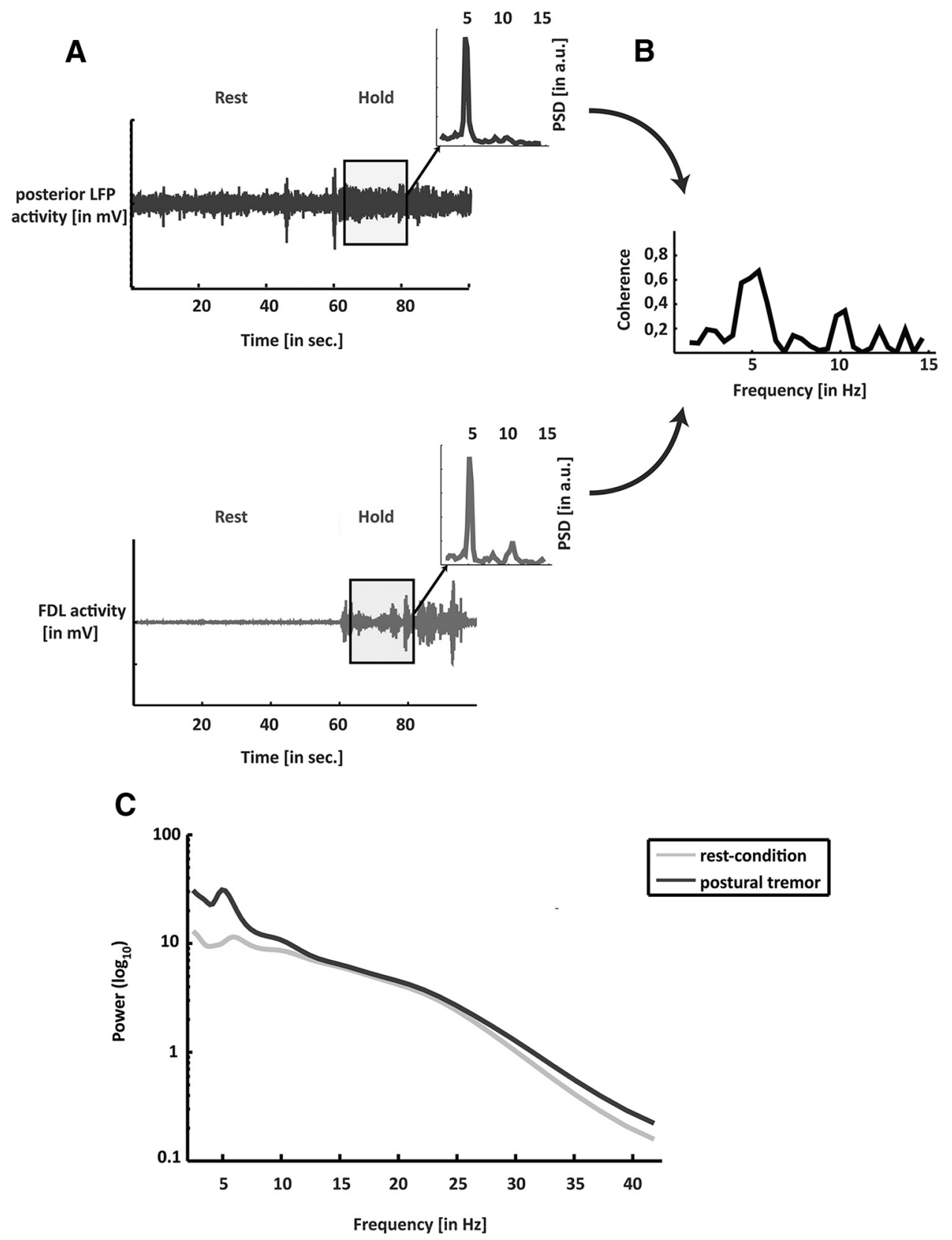

Figure 1. A, Raw data of the LFPs of the posterior electrode of the VLp over time and the contralateral EMG (FDL). The inset shows the power spectrum of the data highlighted in gray. $\boldsymbol{B}$, Coherence of both data tracks (EMG and LFP) for the data in the rectangle. C, Power spectra pooled across all subjects $(n=10)$ for the rest condition (light line) and the hold condition (dark line).

excluded from further processing. Additionally, EMG-LFP combinations without tremor were discarded from further computations. Data were analyzed using our in-house Matlab routines. Before analysis, we applied a phase-neutral high-pass filter at $1.5 \mathrm{~Hz}$, applied a phase-neutral low-pass filter at $46 \mathrm{~Hz}$, and downsampled the data to $500 \mathrm{~Hz}$. Examples of an EMG track and an LFP recording from the posterior electrode with a corresponding power spectrum and EMG-LFP coherence can be found in Figure 1.

Wavelet-derived spectral analysis. The time-frequency representation of any discrete signal $x\left(t_{k}\right)(k=1, \ldots, T)$, with $T$ the data length can be obtained by analyzing the time series by continuous wavelet transforms (WTs). In our case, we used the Morlet wavelet, which is a complexvalued mother wavelet expressed in the following equation (Eq. 1):

$$
\psi(u)=\pi^{-1 / 4} e^{i k_{0} u} e^{-u^{2} / 2}
$$

where $k_{0}$ is the central frequency of $\psi$ and $t$ is the time. We used a modified version of the Morlet software provided by Torrence and
Compo (1998). Morlet wavelets (with $k_{0}=7$ ) are supposed to provide a good balance between time and frequency localization and they have been frequently used in neurophysiological studies in the past (TallonBaudry et al., 1996; Lachaux et al., 2002; Bigot et al., 2011). Thereby, the WT for the given discrete time series $x$, recorded at regularly spaced time points $t_{k}$ with the total length $T$ and for the scale $s$ and the time $t$ are defined as follows (Eq. 2):

$$
W_{x}(s, t)=\sum_{k=1}^{T} x\left(t_{k}\right) \psi_{s, t}{ }^{*}\left(t_{k}\right)
$$

The asterisk denotes the conjugate of a complex number and the following equation (Eq. 3):

$$
\psi_{s, t}\left(t_{k}\right)=\frac{1}{\sqrt{s}} \psi\left(\frac{t_{k}-t}{s}\right)
$$




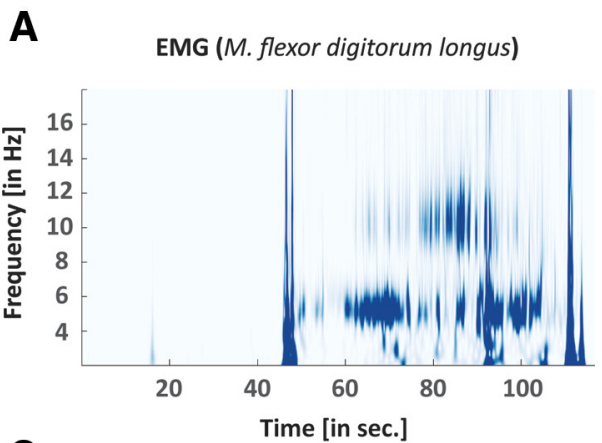

C

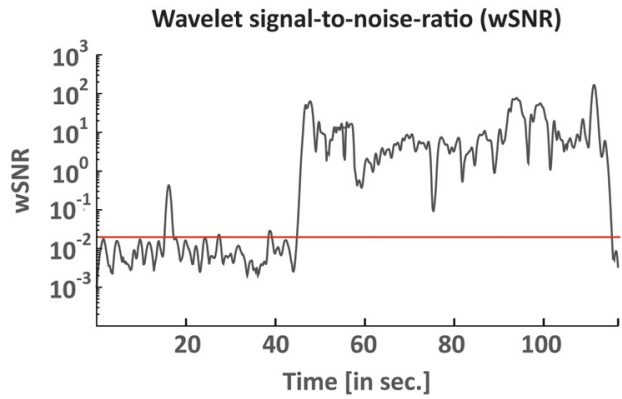

Tremor-activity in the FDL

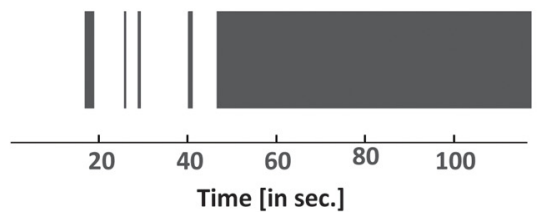

B

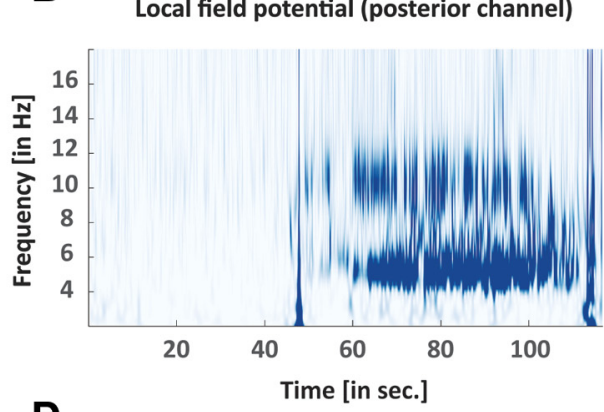

D

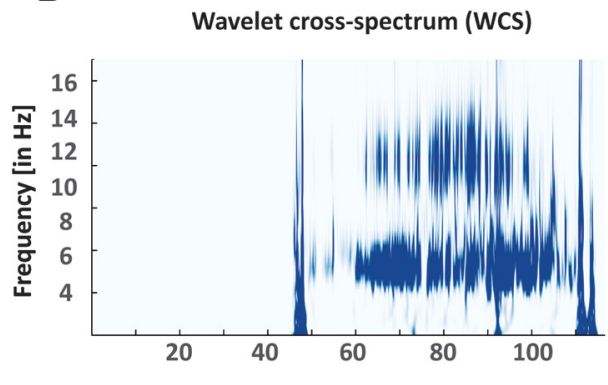

Figure 2. $\quad \boldsymbol{A}, \boldsymbol{B}$, Time-frequency plot of the power spectrum for the EMG (A) and the LFP recording (B). $\boldsymbol{C}$, wSNR of the EMG over time for the tremor frequency band is shown (as per Eq. 9). The red line depicts the $95 \%$ confidence interval, which at the same time is the threshold for tremor activity. Below, tremor activity is represented as binary data. D, WCS for the EMG and the LFP recordings.

Time-frequency representation can be obtained by converting the scale parameter $s$ into a pseudofrequency parameter $\omega$. The WT at frequency $\omega$ and time $t$ can be thus expressed as the following equation (Eq. 4):

$$
W_{x}(\omega, t)=\sum_{k=1}^{T} x\left(t_{k}\right) \sqrt{\frac{\omega}{k_{0}}} \psi\left(\frac{\omega}{k_{0}}\left(t_{k}-t\right)\right)
$$

Given a central frequency $k_{0}=7$, the mean temporal resolution of the wavelet analysis for the tremor band was between 84 and $124 \mathrm{~ms}$ while the frequency resolution was $0.65 \mathrm{~Hz}$ (Torrence and Compo, 1998). The mean spectral density was pooled across subjects for the rest condition and during postural tremor and is represented in Figure 1C. Examples of time-frequency representations of an EMG and LFP recording are shown in Figure $2 A, B$.

WCS density estimation. The WCS has been shown to provide more reliable values for statistical dependence compared with the wavelet coherence, particularly when the number of trials is small (Bigot et al., 2011). As we only recorded single trials at each recording depth, we used the WT from the following equation (Eq. 5), which provided an estimate of the WCS between both EMG $(x)$ and thalamic data $(y)$ :

$$
S_{x y}(\omega, t)=W_{x}(\omega, t) W_{y}^{*}(\omega, t)
$$

where the asterisk denotes the conjugate of a complex number. An example of the WCS of an EMG and an LFP recording are shown in Figure 2D.

Significant WCS density estimation. Significant values of WCS were assessed following the method described by Bigot et al. (2011), which also accounts for high autospectra and is therefore better suited for detecting real dependence between two time series. Therefore, we computed a threshold $\lambda_{a}$ calculated in the following equation (Eq.6):

$$
\hat{\lambda}_{\alpha}=\frac{\hat{\rho}_{x} \hat{\rho}_{y}}{\left(1+\sqrt{\frac{T}{n}}\right)^{2}}\left(-\frac{\log (\alpha / 2)}{n}+\sqrt{\frac{2 \log (\alpha / 2)}{n}}\right)
$$

with $\hat{\rho}_{x}^{2}$ and $\hat{\rho}_{y}^{2}$ being the largest eigenvalue of the empirical covariance matrix of the time series $x$ and $y$, respectively. The theoretical arguments for this formula are described in the work of Bigot and colleagues (2011).

Using this procedure, WCS values in the frequency range between 2 and $8 \mathrm{~Hz}$ above the threshold $\lambda_{a}$ (with $\alpha=0.001$ ) were considered significant. Significant WCS values were represented by a binary variable $\zeta(t)$ as a function of time represented in the following equation (Eq. 7):

$$
\zeta(t)=\left\{\begin{array}{l}
0,\left|S_{x y}(\omega, t)\right|<\hat{\lambda}_{\alpha} \\
1,\left|S_{x y}(\omega, t)\right| \geq \hat{\lambda}_{\alpha}
\end{array}\right.
$$

Time-frequency analysis. The onset of tremor was particularly important for this study, as it was needed for analyzing its relationship with the beginnings of the thalamomuscular coherence. We implemented a method to identify the time intervals, during which oscillatory activity in the tremor range $(2-8 \mathrm{~Hz})$ was present in the EMG. Tremor activity was defined as a spectral peak in the tremor frequency range, significantly above baseline (noise) level. Therefore, the formula for the computation of the signal-to-noise ratio for wavelet-derived time-frequency plots (wSNR) was the quotient of maximum power in the tremor frequency band $(2-8 \mathrm{~Hz})$ at any given point over the average signal power $P(\omega, t)=$ $\left|S_{\mathrm{xx}}(\omega, t)\right|$ expressed in the following equation (Eq. 8): 


$$
w S N R(t)=\frac{\max _{\omega_{a} \leq \omega \leq \omega_{b}}[P(\omega, t)]}{\underset{\omega_{0} \leq \omega \leq \omega_{\max }}{\operatorname{avg}}[P(\omega, t)]}
$$

where $\omega_{a}, \omega_{b}$ are the limits of the tremor band $(2-8 \mathrm{~Hz}), \omega_{\max }=46 \mathrm{~Hz}$ and $\omega_{0}=1 \mathrm{~Hz}$. The threshold for significant tremor activity was computed by means of a bootstrap method using the first $12 \mathrm{~s}$ of the when the subject was in the rest condition and when there was no tremor. Due to the lack of a hold condition without tremor as reference, we adopted a rather conservative significance level. Values of wSNR above the significance level of $p<0.001$ were considered tremor episodes. We confirmed the validity of this formula by visually inspecting the time series of both EMG tracks (EDC and FDL) and testing that this threshold discriminates well between tremor and nontremor intervals. Tremor-on intervals were represented by a binary variable (i.e., tremor being present vs absence of tremor) as a function of time $\tau(t)$, as expressed in the following formula (Eq. 9):

$$
\tau(t)=\left\{\begin{array}{l}
0, w S N R(t)<w S N R_{\text {threshold }} \\
1, w S N R(t) \geq w S N R_{\text {threshold }}
\end{array}\right.
$$

A similar approach has been used before (Hurtado et al., 2005) and was adapted accordingly here. An exemplary wSNR estimation with the corresponding EMG track is shown in Figure $2 C$.

Statistical analyses. Statistical analyses were carried out using the software SPSS Statistics (IBM), Stata (StataCorp) and Excel (Microsoft).

Temporal relationship of coherence and tremor. Our first aim was to quantify the amount of time during which coherence coincided with visible tremor. Hence, we computed the times during which there was tremor with thalamomuscular coherence $[\zeta(t)=1]$ and put them into relation with the total tremor time $[\tau(t)=1]$, according to the following formula (Eq. 10):

$$
\frac{\int_{t_{0}}^{T} \tau(t) \zeta(t) d t}{\int_{t_{0}}^{T} \tau(t) d t}
$$

Likewise, the ratio between intervals without tremor but with significant thalamomuscular coherence $[\zeta(t)=1]$ and the total time during which there was no coherence $[1-\zeta(t)]$ was calculated as follows (Eq. 11):

$$
\frac{\int_{t_{0}}^{T}(1-\tau(t)) \zeta(t) d t}{\int_{t_{0}}^{T}(1-\zeta(t)) d t}
$$

The values for time with tremor and coherence were averaged for every subject and subsequently compared between locations identified as "tremor clusters" and other locations with the nonparametric Wilcoxon signed-rank test. For the detection and verification of these tremor clusters, see Pedrosa et al. (2012).

Spatial differences in the different electrode localizations. Finally, we wanted to investigate specific anatomical and temporal patterns of the emergence of significant WCS for the electrode locations in the subjects (central, anterior, medial, lateral, and posterior). We performed a linear regression adjusted for clustering by subjects [Stata option: vce(cluster)] of the delay between tremor and significant WCS $(d \mathrm{t})$ on location (coded by four indicator variables). Beforehand, the highest $1 \%$ of the data was trimmed off for each location to reduce the influence of outliers. Pairwise comparisons were not adjusted for multiple testing to retain statistical power.

\section{Results}

\section{General data}

All patients presented with a severe and disabling postural tremor of the upper extremities with an average tremor frequency of $4.6 \pm 0.8 \mathrm{~Hz}$. LFPs were recorded for four patients in the left and for six patients in the right VLp. During the rest condition, none of the subjects showed tremulous activity. In total, we analyzed 335 different recordings of LFP activity at an average of 8.6 recording depths per ET patient. This corresponds to an average of 3.9 trajectories per patient. Finally, 670 EMG tracks (335 EDC and 335 FDL recordings) were analyzed.

\section{Power spectral density between both conditions}

Power spectral density differed between both conditions. There was a peak around the tremor frequency band during the hold condition. Nevertheless, also during the rest condition, there was activity in the $\theta$ band $(4-7 \mathrm{~Hz})$ across all patients. This activity coincided in parts with the tremor activity (as the tremor frequency band is $2-8 \mathrm{~Hz}$ ). However, the detected peak frequency in the $\theta$ band during rest was higher than the peak frequency during tremor. The pooled power spectra are also visualized in Figure $1 C$.

\section{Temporal evolution of thalamomuscular coherence}

When comparing tremor onset and the onset of significant coherence, tremor activity in the EMG emerged on average $220 \pm$ $460 \mathrm{~ms}$ before significant thalamomuscular coherence. Additionally, clustered linear regression revealed that the localization of the electrode had a statistical effect on the onset of coherence $\left(F_{(4,9)}=6.70, p=0.009\right)$. The lateral electrodes had a significantly longer latency than the central electrodes $(p<0.05$ in pairwise comparisons). In contrast, there was no statistical difference in the delay between tremor onset and onset of coherence between tremor clusters and nontremor clusters. These results are all visualized in Figures 3 and 4.

\section{Thalamomuscular coherence}

Thalamomuscular coherence $[\zeta(t)=1]$ was detectable in $83.9 \pm$ $19.3 \%$ of the times in which tremor was present $[\tau(t)=1]$. Regarding the two groups, tremor clusters and nontremor clusters, the former had a significantly higher amount of coincidence of tremor and WCS (median, 92.6\%) compared with recording levels that were not tremor clusters (median, 85.4\%). This difference was statistically significant $(z=-2.50, p=0.013)$ and corresponded to an effect size of $r=-0.78$. Otherwise, times without tremor $[\tau(t)=0]$ showed a significant coherence in $3.41 \%$ of tremor clusters, while in heights without particular overall coherence times without tremor showed simultaneous significant coherence $5.47 \%$ of the time. This difference was not statistically significant $(z=-1.60, p>0.05)$. Results concerning differences between tremor clusters and nontremor clusters are illustrated in Figure 4.

\section{Discussion}

We applied time-dependent linear analyses to explore temporal relationships between tremor onset and emergence of thalamomuscular coherence in 10 ET patients undergoing DBS surgery. Thereby, tremor onset preceded thalamomuscular coherence and the latter remained present most of the time during tremor.

\section{Methodological considerations}

Recently, time-dependent signal analysis has gained importance for interpreting oscillatory behavior of neurophysiological sig- 
A

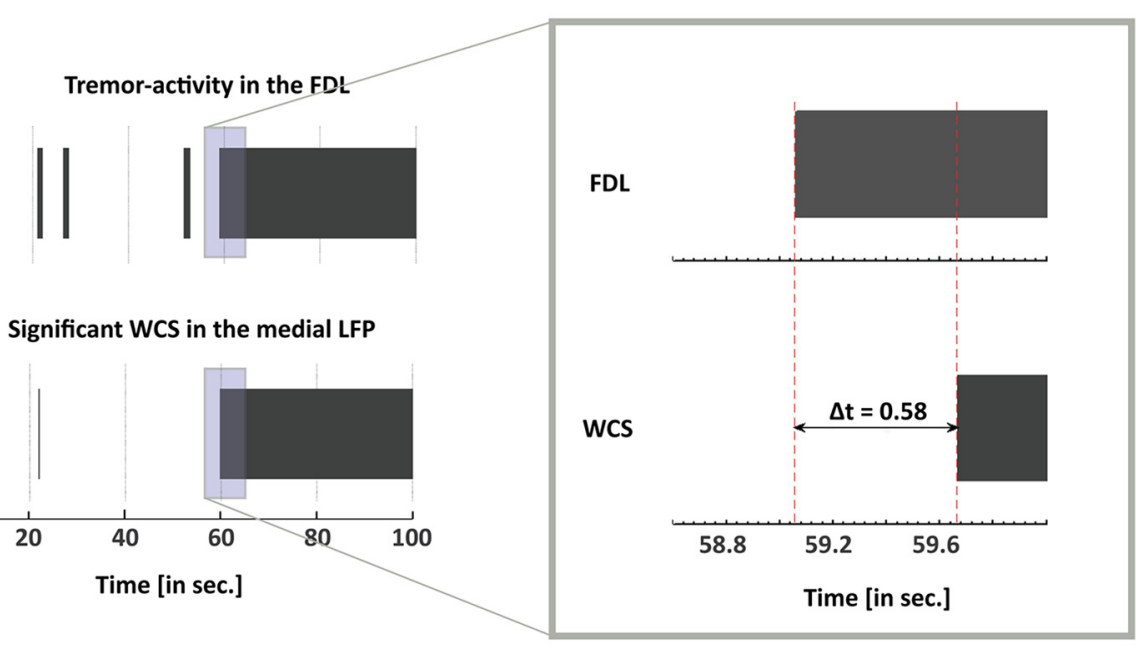

B

Temporal reationship between tremor onset and onset of significant cross correlation (WCS)

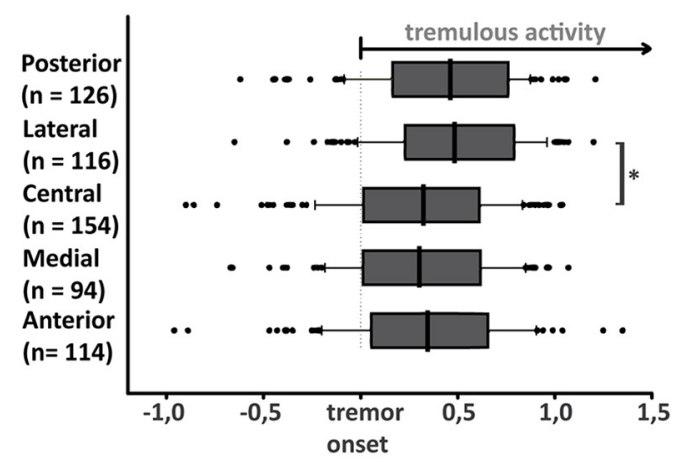

Mean $\Delta \mathrm{t}[$ in sec.]

Figure 3. A, Binary data for the presence of significant WCS (lower plot) and significant tremor activity (upper plot) over the course of time in a representative subject. The onset of tremulous activity was at $\sim 60$ s (Figs. 1, 2). The right side shows the enhanced period marked with a rectangle. Thereby, $\Delta$ t is the difference between the onset of tremor and the begin of significant coherence. $B$, Boxplot of the mean time difference between tremor onset and WCS onset for the five locations of recordings within one height. Asterisk depicts the statistically significant difference of $\Delta t$ between central and lateral electrodes $(p=0.049)$.

nals (Varela et al., 2001; Schnitzler and Gross, 2005). We applied wavelet-derived methods as interdependency measure for different reasons. First, WCS may overcome the limitation of nonstationary signals. Second, probabilistic thresholds for WCS appear more robust than wavelet coherence significance levels (Bigot et al., 2011). However, it should be stressed that comparing theoretical analyses for WCS detection with data-driven approaches (as used for tremor-onset detection) constitutes an important caveat. Nevertheless, a data-driven approach for wavelet analyses was hampered by thalamic $\theta$ activity at rest (Sarnthein et al., 2005). Therefore, our results await further confirmation. Last, time restrictions during surgery resulted in one trial per recording location. In this context, wavelet-derived methods show reliable results in single-trial datasets (Lachaux et al., 2002). Overall, our results provide valuable insights into linear interdependencies, while in turn not considering nonlinear relationships.

However, the results of linear interdependencies are impossible to completely separate from the results of nonlinear interdependencies. For instance, linear analyses may also reveal aspects of nonlinear coupling in ET (Timmer et al., 1993, 2000). Furthermore, nonlinear interdependencies are not necessarily superior but rather assess distinct aspects of signal coupling. The importance of nonlinear measurements was recently corroborated with the detection of phase dependency for efficient DBS pulses (Cagnan et al., 2013). Given the frequent nonlinear phenomena in neurophysiological processes, further work contemplating nonlinear couplings in ET is required.

Finally, another limitation needs to be borne in mind. Using rest condition as baseline, the detection of false early tremor onset is possible because EMG activity of arm movements was not taken into account. Owing to disease characteristics, isometric contractions without tremor was impossible. Because of tremor harmonics in the EMG (e.g., in double tremor frequency), attempts aiming at replacing tremor-band information $(2-8 \mathrm{~Hz})$ by surrogate data produced problematic results. We therefore used rest as baseline and in turn applied stringent significance levels for threshold generation.

\section{Dynamics of thalamomuscular coupling}

Although thalamomuscular coupling has been traced in magneto-encephalographic (Timmermann et al., 2003; Schnitzler et al., 2009) and electrophysiological studies (Marsden et al., 2000), little is known about the temporal properties of such coupling. One reason might be difficulties of detecting delay times in narrow-band signals with conventional phase estimation (Lindemann et al., 2001; Müller et al., 2003). Hence, we measured 
A

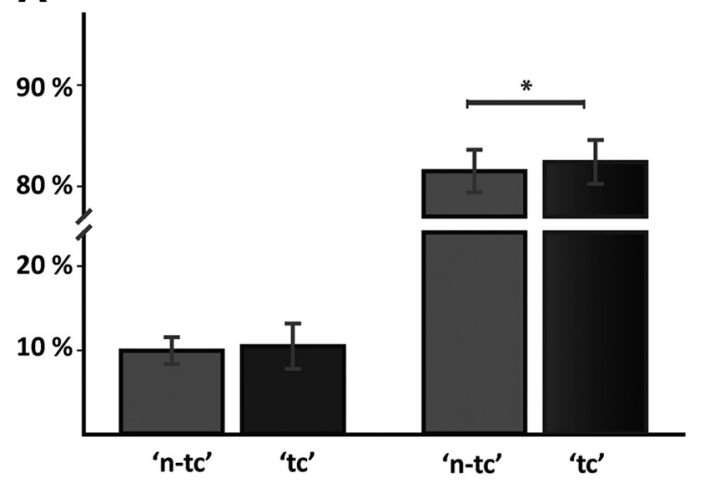

B

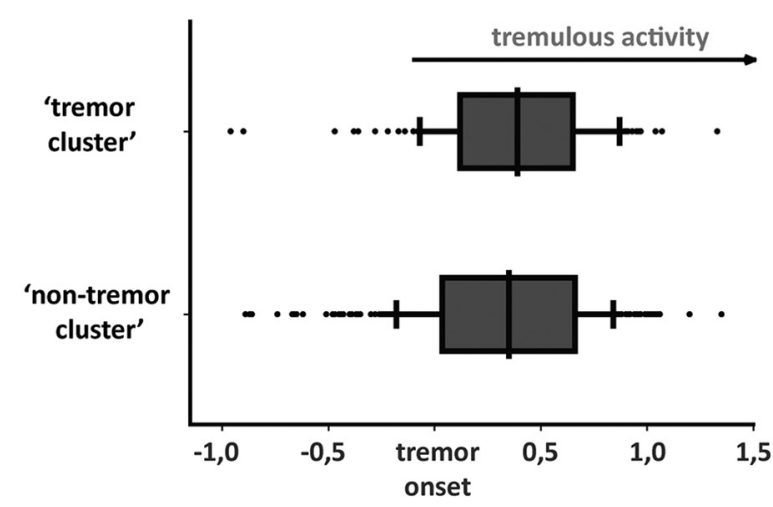

Mean $\Delta t$ [in sec.]

Figure 4. A, Time during which there is statistically significant WCS without tremor (left side), and coincidence between tremor and WCS (right side), separated on whether height had been identified as tremor cluster (dark column, 'tc') or not (bright column, ' $\mathrm{n}$-tc'). Asterisk indicates that the difference between the coincidence of tremor and WCS was significantly superior when recording depth was a tremor cluster. $\boldsymbol{B}$, Delay of tremor onset and onset of significant WCS depending upon whether heights are tremor clusters or not. This difference was not statistically significant.

time-dependent WCS. With a similar approach, intermittent pallidomuscular coherence was detected in parkinsonian patients. This group hypothesized episodes of either synchronizing or desynchronizing activity between brain and muscles (Hurtado et al., 2005). While that study looked at a different disease and looked at different targets, there may be good reasons to reconcile their results with ours showing inconstant thalamomuscular coupling. First, current opinion has switched from single oscillators driving ET toward the emergence of a synchronized tremor network comprising cortical, subcortical, and cerebellar areas (Raethjen and Deuschl, 2012). Within these areas, somatotopically organized pathological activity was consistently demonstrated (Helmich, 2013). Our results support this, as thalamomuscular coherence coincided with tremor activity in a significantly higher percentage at tremor cluster locations (Pedrosa et al., 2012). Thus, if inconsistent coupling is traceable in parts of this tremor network, we consider it likely that it will manifest in the VLp as well. Second, output from the internal part of the globus pallidus (GPi) mainly targets the VLp. Similarities in both regions would therefore not be surprising. However, it should be indicated that the GPi rather projects to anterior portions of the VLp. Finally, we have shown comparable behavior of tremor in the VLp for both Parkinson's disease and ET (Pedrosa et al., 2012), suggesting common mechanisms of thalamic tremor propagation. Thus, we hypothesize inconstant coupling with the periphery across the tremor network as shared property of different tremor entities.

\section{Tremor onset before thalamomuscular coherence}

The pivotal role of the thalamus for tremor was recognized in the context of efficacious lesional approaches, particularly in regions showing high densities of "tremor cells." These regions manifest with high thalamomuscular coherence at the tremor frequency (Hua et al., 1998; Marsden et al., 2000) and appear with a topographic organization (Pedrosa et al., 2012). This organization is to be expected given the somatotopical cerebellar and pallidal input into the VLp (Ilinsky and Kultas-Ilinsky, 1984; Sakai et al., 1996) and the extensive information transfer with the motor cortex (Strick, 1976). Reciprocal thalamocortical information transfer was also detected in ET compared with physiologic voluntary movements (Muthuraman et al., 2012). As cortical structures were disregarded in this study, no direct conclusions can be drawn. However, recent literature suggests sensorimotor regions driving trembling muscles (Govindan et al., 2006; Schelter et al., 2009). Considering our results, temporal evolution of tremor and thalamomuscular coherence might thus be as follows: motor cortex drives muscles to tremble, while somatosensory (muscle) feedback closes the loop, producing thalamomuscular coherence. This sequence certainly simplifies tremor generation, leaving aside the possibility of, for example, subcortical structures initiating tremor. Accordingly, previous research has indicated tremor generation due to abnormal pallidal activation in Parkinson's disease (Helmich et al., 2011) or decreased GABAergic drive from the dentate nucleus in ET (Paris-Robidas et al., 2012). This outlines the need for more research scrutinizing cortical and subcortical contributions for tremor generation, which goes beyond the scope of this study. Nevertheless, with our results of a delay of $\sim 200$ ms between tremor onset and coherence onset in mind, several aspects attract attention. The time is longer than corticospinal delay (Rothwell, 1991) but particularly longer than delays for direct somatosensory input (Fokin and Veskov, 1972), making an indirect feedback more likely. In consideration of the putative cerebellar affection in ET, our findings corroborate a disturbed sensory feedback integration at a cerebellar level, e.g., via spinocerebellar tracts. Another possibility involves thalamic affection or impairment of the extensive connections between cerebellum and VLp (Hirai and Jones, 1989). Similar ideas about the importance of reafferent thalamic input via cerebellar nuclei for tremor in general have been brought up before (Volkmann et al., 1996).

This theory of the VLp integrating arriving peripheral and central tremor signals is appealing for several reasons. Spatial concordance of somatosensory cells and tremor cells (i.e., cells showing strong thalamomuscular coherence) were detected in the VLps of primates (Stepniewska et al., 2003). This indicates the importance of sensory feedback for tremor and explains significant differences within one recording depth in our results. Thereby, tremor signals might spread inside the thalamus evolving into coherence. Besides, it could explain the irregular tremor initiation seen in clinical examination and the lack of thalamomuscular coherence in studies regarding only short episodes due 
to insufficient time to entrain thalamic cells to coherence (Halliday et al., 2000).

Apart from neurophysiologic evidence, clinical observation corroborates the importance of somatosensory input in ET. Tremor amplitude and phase are susceptible to limb perturbations (Lee and Stein, 1981; Elble et al., 1992). Moreover, tremor may worsen after peripheral nerve damage, e.g., in paraproteinaemic/inflammatory neuropathies (Saifee et al., 2013).

Our findings therefore suggest a spread of tremor signals within the thalamus after indirect feedback, e.g., via the cerebellum. Accordingly, thalamomuscular coherence is likely the "egg," not the "hen."

\section{Thalamomuscular coherence and DBS}

Severe ET can be treated effectively with thalamic DBS. Accordingly, understanding the pathophysiology of thalamic tremor signals appears to be essential for refining DBS regimes and pinpointing their working mechanisms. One possible working mechanism is the attenuation of afferent thalamic transmission (Anderson et al., 2006) as local applications of inhibitory agents suppress tremor (Dostrovsky et al., 1993; Pahapill et al., 1999) and as somatosensory signals appear to play a substantial role for tremor entrainment. Moreover, these findings reflect the shortcomings of thalamomuscular coherence as a marker of imminent tremor onset.

Markers preceding tremor onset are highly desirable, as they could be used for "closed-loop" DBS and, thus, reduce stimulation-induced side effects (Deuschl et al., 2011). As already stated, thalamomuscular coherence is not well suited for this purpose. Although generally present during tremor, it emerges after tremor onset and its intensity fluctuates during the course of tremor activity. Moreover, it requires sensing of contralateral extremities, making it more complex than simultaneous sensing and stimulation at one place. Therefore, intracerebral markers as spectral power changes might be particularly interesting. Unfortunately, we could not detect thalamic spectral power changes in the tremor frequency band. Possibly, $\theta$ activity during rest as demonstrated before (Sarnthein et al., 2005) and attributed to afferent input to the motor thalamus (Kane et al., 2009) hampered a baseline definition. An alternative intracerebral marker could be enhanced bidirectional thalamocortical communication, which is exclusively traceable during pathological tremors (Muthuraman et al., 2012). The authors speculated that this activity is responsible for increases in thalamic subthreshold activity before arm elevation, and possibly explains the lack of resting tremor in ET. Future studies exploring corticothalamic interdependencies might add information to identify closed-loop DBS markers.

In summary, we demonstrate that tremor onset precedes the beginning of coherence, indicating the role of somatosensory feedback for ET. Given the relative delay of thalamomuscular coherence, its applicability as marker for closed-loop DBS appears limited. Therefore, peripheral tremor signals remain the most reliable biomarkers for on-demand stimulation.

\section{References}

Anderson TR, Hu B, Iremonger K, Kiss ZH (2006) Selective attenuation of afferent synaptic transmission as a mechanism of thalamic deep brain stimulation-induced tremor arrest. J Neurosci 26:841-850. CrossRef Medline

Barbe MT, Liebhart L, Runge M, Deyng J, Florin E, Wojtecki L, Schnitzler A, Allert N, Sturm V, Fink GR, Maarouf M, Timmermann L (2011) Deep brain stimulation of the ventral intermediate nucleus in patients with essential tremor: stimulation below intercommissural line is more effi- cient but equally effective as stimulation above. Exp Neurol 230:131-137. CrossRef Medline

Bigot J, Longcamp M, Dal Maso F, Amarantini D (2011) A new statistical test based on the wavelet cross-spectrum to detect time-frequency dependence between non-stationary signals: application to the analysis of cortico-muscular interactions. Neuroimage 55:1504-1518. CrossRef Medline

Blomstedt P, Fytagoridis A, Tisch S (2009) Deep brain stimulation of the posterior subthalamic area in the treatment of tremor. Acta Neurochir (Wien) 151:31-36. CrossRef Medline

Brown P (2003) Oscillatory nature of human basal ganglia activity: relationship to the pathophysiology of Parkinson's disease. Mov Disord 18:357363. CrossRef Medline

Cagnan H, Brittain JS, Little S, Foltynie T, Limousin P, Zrinzo L, Hariz M, Joint C, Fitzgerald J, Green AL, Aziz T, Brown P (2013) Phase dependent modulation of tremor amplitude in essential tremor through thalamic stimulation. Brain 136:3062-3075. CrossRef Medline

Deuschl G, Krack P, Lauk M, Timmer J (1996) Clinical neurophysiology of tremor. J Clin Neurophysiol 13:110-121. CrossRef Medline

Deuschl G, Bain P, Brin M (1998) Consensus statement of the Movement Disorder Society on tremor. Ad Hoc Scientific Committee. Mov Disord 13 [suppl 3]:2-23. Medline

Deuschl G, Raethjen J, Hellriegel H, Elble R (2011) Treatment of patients with essential tremor. Lancet Neurol 10:148-161. CrossRef Medline

Dostrovsky JO, Sher GD, Davis KD, Parrent AG, Hutchison WD, Tasker RR (1993) Microinjection of lidocaine into human thalamus: a useful tool in stereotactic surgery. Stereotact Funct Neurosurg 60:168-174. CrossRef Medline

Elble RJ, Higgins C, Moody CJ (1987) Stretch reflex oscillations and essential tremor. J Neurol Neurosurg Psychiatry 50:691-698. CrossRef Medline

Elble RJ, Higgins C, Hughes L (1992) Phase resetting and frequency entrainment of essential tremor. Exp Neurol 116:355-361. CrossRef Medline

Fokin VF, Veskov R (1972) The spatial-temporal characteristics of evoked potentials in the posterior ventrolateral nucleus of the cat thalamus (in Russian). Neirofiziologiia 4:439-446. Medline

Govindan RB, Raethjen J, Arning K, Kopper F, Deuschl G (2006) Time delay and partial coherence analyses to identify cortical connectivities. Biol Cybern 94:262-275. CrossRef Medline

Halliday DM, Conway BA, Farmer SF, Shahani U, Russell AJ, Rosenberg JR (2000) Coherence between low-frequency activation of the motor cortex and tremor in patients with essential tremor. Lancet 355:1149-1153. CrossRef Medline

Helmich RC (2013) The distributed somatotopy of tremor: a window into the motor system. Exp Neurol 241:156-158. CrossRef Medline

Helmich RC, Janssen MJ, Oyen WJ, Bloem BR, Toni I (2011) Pallidal dysfunction drives a cerebellothalamic circuit into Parkinson tremor. Ann Neurol 69:269-281. CrossRef

Hirai T, Jones EG (1989) A new parcellation of the human thalamus on the basis of histochemical staining. Brain Res Brain Res Rev 14:1-34. Medline

Hua SE, Lenz FA, Zirh TA, Reich SG, Dougherty PM (1998) Thalamic neuronal activity correlated with essential tremor. J Neurol Neurosurg Psychiatry 64:273-276. Medline

Hurtado JM, Rubchinsky LL, Sigvardt KA, Wheelock VL, Pappas CT (2005) Temporal evolution of oscillations and synchrony in GPi/muscle pairs in Parkinson's disease. J Neurophysiol 93:1569-1584. Medline

Ilinsky IA, Kultas-Ilinsky K (1984) An autoradiographic study of topographical relationships between pallidal and cerebellar projections to the cat thalamus. Exp Brain Res 54:95-106. Medline

Jenkins IH, Bain PG, Colebatch JG, Thompson PD, Findley LJ, Frackowiak RS, Marsden CD, Brooks DJ (1993) A positron emission tomography study of essential tremor: evidence for overactivity of cerebellar connections. Ann Neurol 34:82-90. Medline

Kane A, Hutchison WD, Hodaie M, Lozano AM, Dostrovsky JO (2009) Enhanced synchronization of thalamic theta band local field potentials in patients with essential tremor. Exp Neurol 217:171-176. CrossRef Medline

Lachaux JP, Lutz A, Rudrauf D, Cosmelli D, Le Van Quyen M, Martinerie J, Varela F (2002) Estimating the time-course of coherence between single-trial brain signals: an introduction to wavelet coherence. Neurophysiol Clin 32:157-174. Medline

Lee RG, Stein RB (1981) Resetting of tremor by mechanical perturbations: a 
comparison of essential tremor and parkinsonian tremor. Ann Neurol 10:523-531. Medline

Lindemann M, Raethjen J, Timmer J, Deuschl G, Pfister G (2001) Delay estimation for cortico-peripheral relations. J Neurosci Methods 111:127139. Medline

Marsden JF, Ashby P, Limousin-Dowsey P, Rothwell JC, Brown P (2000) Coherence between cerebellar thalamus, cortex and muscle in man: cerebellar thalamus interactions. Brain 123:1459-1470. CrossRef Medline

Müller T, Lauk M, Reinhard M, Hetzel A, Lücking CH, Timmer J (2003) Estimation of delay times in biological systems. Ann Biomed Eng 31: 1423-1439. Medline

Muthuraman M, Heute U, Arning K, Anwar AR, Elble R, Deuschl G, Raethjen J (2012) Oscillating central motor networks in pathological tremors and voluntary movements. What makes the difference? Neuroimage 60:13311339. CrossRef Medline

Pahapill PA, Levy R, Dostrovsky JO, Davis KD, Rezai AR, Tasker RR, Lozano AM (1999) Tremor arrest with thalamic microinjections of muscimol in patients with essential tremor. Ann Neurol 46:249-252. Medline

Paris-Robidas S, Brochu E, Sintes M, Emond V, Bousquet M, Vandal M, Pilote M, Tremblay C, Di Paolo T, Rajput AH, Rajput A, Calon F (2012) Defective dentate nucleus GABA receptors in essential tremor. Brain 135: 105-116. CrossRef Medline

Pedrosa DJ, Reck C, Florin E, Pauls KA, Maarouf M, Wojtecki L, Dafsari HS, Sturm V, Schnitzler A, Fink GR, Timmermann L (2012) Essential tremor and tremor in Parkinson's disease are associated with distinct 'tremor clusters' in the ventral thalamus. Exp Neurol 237:435-443. CrossRef Medline

Raethjen J, Deuschl G (2012) The oscillating central network of essential tremor. Clin Neurophysiol 123:61-64. CrossRef Medline

Raethjen J, Govindan RB, Kopper F, Muthuraman M, Deuschl G (2007) Cortical involvement in the generation of essential tremor. J Neurophysiol 97:3219-3228. Medline

Rothwell JC (1991) Physiological studies of electric and magnetic stimulation of the human brain. Electroencephalogr Clin Neurophysiol Suppl 43:29-35. Medline

Rouse AG, Stanslaski SR, Cong P, Jensen RM, Afshar P, Ullestad D, Gupta R, Molnar GF, Moran DW, Denison TJ (2011) A chronic generalized bidirectional brain-machine interface. J Neural Eng 8:036018. CrossRef Medline

Saifee TA, Schwingenschuh P, Reilly MM, Lunn MP, Katschnig P, Kassavetis P, Pareés I, Manji H, Bhatia K, Rothwell JC, Edwards MJ (2013) Tremor in inflammatory neuropathies. J Neurol Neurosurg Psychiatry 84:12821287. CrossRef Medline

Sakai ST, Inase M, Tanji J (1996) Comparison of cerebellothalamic and pallidothalamic projections in the monkey (Macaca fuscata): a double anterograde labeling study. J Comp Neurol 368:215-228. Medline

Sarnthein J, Morel A, von Stein A, Jeanmonod D (2005) Thalamocortical theta coherence in neurological patients at rest and during a working memory task. Int J Psychophysiol 57:87-96. CrossRef Medline

Schaltenbrand G, Wahren W, Hassler R (1977) Atlas for stereotaxy of the human brain, 2nd edition. Chicago: G. Thieme.

Schelter B, Timmer J, Eichler M (2009) Assessing the strength of directed influences among neural signals using renormalized partial directed coherence. J Neurosci Methods 179:121-130. CrossRef Medline

Schnitzler A, Gross J (2005) Normal and pathological oscillatory communication in the brain. Nat Rev Neurosci 6:285-296. Medline

Schnitzler A, Münks C, Butz M, Timmermann L, Gross J (2009) Synchronized brain network associated with essential tremor as revealed by magnetoencephalography. Mov Disord 24:1629-1635. CrossRef Medline

Sixel-Döring F, Benecke R, Fogel W, Hilker R, Kupsch A, Lange M, Schrader C, Timmermann L, Volkmann J, Deuschl G (2009) Deep brain stimulation for essential tremor. Consensus recommendations of the German Deep Brain Stimulation Association (in German). Nervenarzt 80:662665. CrossRef Medline

Stepniewska I, Sakai ST, Qi HX, Kaas JH (2003) Somatosensory input to the ventrolateral thalamic region in the macaque monkey: potential substrate for parkinsonian tremor. J Comp Neurol 455:378-395. Medline

Strick PL (1976) Anatomical analysis of ventrolateral thalamic input to primate motor cortex. J Neurophysiol 39:1020-1031. Medline

Tallon-Baudry C, Bertrand O, Delpuech C, Pernier J (1996) Stimulus specificity of phase-locked and non-phase-locked $40 \mathrm{~Hz}$ visual responses in human. J Neurosci 16:4240-4249. Medline

Timmer J, Gantert C, Deuschl G, Honerkamp J (1993) Characteristics of hand tremor time series. Biol Cybern 70:75-80. Medline

Timmer J, Haussler S, Lauk M, Lucking CH (2000) Pathological tremors: deterministic chaos or nonlinear stochastic oscillators? Chaos 10:278288. Medline

Timmermann L, Gross J, Dirks M, Volkmann J, Freund HJ, Schnitzler A (2003) The cerebral oscillatory network of parkinsonian resting tremor. Brain 126:199-212. Medline

Torrence C, Compo GP (1998) A practical guide to wavelet analysis. Bull Amer Meteor Soc 79:61-78.

Varela F, Lachaux JP, Rodriguez E, Martinerie J (2001) The brainweb: phase synchronization and large-scale integration. Nat Rev Neurosci 2:229239. Medline

Volkmann J, Joliot M, Mogilner A, Ioannides AA, Lado F, Fazzini E, Ribary U, Llinás R (1996) Central motor loop oscillations in parkinsonian resting tremor revealed by magnetoencephalography. Neurology 46:1359-1370. Medline

Wills AJ, Jenkins IH, Thompson PD, Findley LJ, Brooks DJ (1994) Red nuclear and cerebellar but no olivary activation associated with essential tremor: a positron emission tomographic study. Ann Neurol 36:636-642. Medline 